\title{
Facts, Values, and Objectivity in the Human Sciences
}

\author{
PAUL HEALY \\ University College, Cork, Ireland
}

In recent times the tenability of a "value neutral" conception of social inquiry has come under increasing scrutiny. The critique of the traditional model is grounded in a reappraisal of the relationship of facts and values on the levels of both methodology and lived experience. The present essay reviews some major elements in the critique of value neutrality, and on the basis of a reappraisal of the fact/value relationship, argues for an alternative conception of the objectivity of the complex process of social inquiry.

\section{I}

The traditional value neutral model of research in the human sciences is predicated on the assumption that the investigator can and does pursue his research into the social world in a totally disinterested way, unaffected by his interests and values. This model presupposes also that the social world encompasses a domain of "brute facts," which are readily accessible via standard scientific procedures, generally construed on the model of those employed in the physical sciences. These social facts, it is assumed, can be identified, observed, and integrated in a meaningful way from a purely neutral viewpoint and in a quasi-mathematical fashion, and on this basis, yield a completely objective answer to the problem under investigation. Thus, as its name clearly implies, this conception of social research presupposes the exclusion of values as a precondition of objectivity.

However, the tenability and cogency of the value neutral model has been forcefully challenged by some social theorists who, in contrast, see the presence of valuational considerations as a necessary condition for the conduct of social inquiry. Thus, Gunnar Myrdal, for example, writes:

we employ and we need value premises in making scientific observations of facts and in analyzing their causal interrelations. Chaos does not organize itself into cosmos. We need viewpoints 
and they presume valuations. social science' is, from this nonsense. It never existed exist. '
A 'disinterested viewpoint, pure and it will never

The reasons for Myrdal's strong reaction to the traditional model become more apparent in the light of the following considerations.

Experience with the process of social research makes it clear that neither research problems nor research frameworks present themselves to the scientist ex nihilo. On the contrary, a problem area in need of investigation becomes apparent to the investigator only on the basis of certain questions and interests which the researcher has come to see as significant. In this way, even the identification of a research problem seems to depend on the interests and values of the scientist. A fortiori, the construction of an appropriate research framework for the investigation of a problem area is likewise guided by the researcher's questions and interests. But these interests which influence the selection of a research problem and the construction of a research framework clearly imply a context of meaning and value. Furthermore, the role of values in the conduct of scientific inquiry becomes more, rather than less, apparent when we consider what is involved in the collection of empirical data regarding the phenomena under investigation. Here, it would seem that interests and values are necessarily involved in the selection of certain "facts" (from out of the virtual infinity of phenomena that impinge on our senses) as relevant to the resolution of the problem under investigation. That is to say, a viewpoint, a research interest, seems necessary to focus the selection and observation of relevant "facts," and thereafter, to systematically integrate these in a manner which could yield an answer to the research problem. As Myrdal notes, only a "naive empiricism" could maintain that "if we observe, and continue to observe, reality without any preconceptions, the facts will somehow organize themselves into a system which is assumed to pre-exist." In contrast to such a naive empiricism, however, Myrdal affirms that, "without questions there are no answers. And the answers are preconceived in the formulation of the questions. The questions express our interests in the matter. These interests can never be purely scientific. They are choices, the products of our valuations.... [ (T)he factual analysis cannot be carried out except when guided by the value premise." 2 Finally, Myrdal concludes that, contrary to what is assumed by the value neutral conception, "we can strive to make our thinking rational in spite of this lviz. in spite of the necessary inclusion of values in social scientific analysis], but only by facing the valuations, not by evading them.") (Surprising 
though it may seem, in view of the fact that the origin of the notion of value neutrality is often attributed to him, Weber himself in places makes similar comments on the role of evaluative ideas in social research.)" Ii the light of such criticism of the value neutral model of inquiry, the present essay is devoted to the attempt to delineate a model of objective social inquiry which does not presuppose the exclusion of values and interests.

However, further reflection reveals that the matter is still more complex than that posed by Myrdal and that Myrdal's analysis, critical though it is of the traditional empiricist framework, still, in a sense, remains within that framework. This is because Myrdal's criticism still presupposes that there are separate domains of "facts" and "values" and that the former constitute the subject-matter of social inquiry. For some time now, however, phenomenologists, amongst others, have queried the tenability of the assumption that in the world of lived experience social facts and social values can be easily separated, and that the former, in contradistinction to the latter, constitute the object of research in the human sciences. The phenomenological arguments in this regard have recently been forcefully articulated by Calvin schrag in his radical reflections on the origin of the human sciences. 5

Schrag strongly challenges the tenability of initially positing two separate domains of facts and values. For once this assumption is made, all subsequent problems will be posed within an empiricist framework wherein "discrete, atomistic, and nonintentional" facts are already set in opposition to values because the former are already taken in "abstraction from the flow of lived-through experience as it emerges and develops in a concrete life-world" (pp. 84-86). To gain a proper perspective on the fact/value issue--one which holds open the possibility of a resolution of this vexing problem because it has not prematurely presupposed a separation--it is necessary to return to reflect on the domain of lived experience, where, Schrag argues, we will find that facts and values are initially integrated and inseparable. We must return, that is, to the integrated origin of facts and values "within the lived relations of man with his social world" (p. 85 ). This starting-point in the domain of lived experience is appropriate for the consideration of the methodological relation of facts and values because it is also in our "prescientific concerns and interests" that the sciences have their origin and point of departure (e.g., pp. 68-69).

Drawing on the analyses of earlier phenomenologists, Schrag argues that in the life world we encounter a domain of meaning-formation in which social events and phenomena are apprehended in a pre-thematic 
fashion. In particular, on this level of lived experience, we find that "the embodied experiencer as living agent is not separated from his value-laden acts" and that this "originary setting or milieu of human thought, language, and action is at the same time a horizon of world-values." Valuation, we see, is itself "a mode of existing in the world" (p. 94).

On the level of lived experience, then, it makes no sense to talk of facts in opposition to values nor of values in opposition to facts. Accordingly, on Schrag's account, there are no "brute" facts in the empiricist sense. The analysis of facts in the social world, if it is to be undertaken, must proceed in terms of what Schrag calls "world-facts." These "world facts," Schrag explains, "as distinct from the facts of an abstracted empiricism, are configurative rather than atomistic in character" (p. 88 ). As configuarative, world facts are present in our experience "as figures with horizional backgrounds"; as experienced. "they implicate an experiencer," and they display "an intentional structure in which understanding and interpretation are already operating." And, most importantly, within the sphere of world facts, facts and values are inseparabile and equiprimordial (pp. 89-90). It is here that we discover "the sphere of origin in which configurative, intentional world-fact and world-valuation mix and mingle" (p. 94).

Thus, on the basis of Schrag's analysis of the primordial inseparability of facts and values in the social world, we see that if "facts" are said to be the subject matter of social research, these cannot be "brute facts" in the empiricist sense but must rather be the "intentionality-laden world facts of lived experience." The question is, therefore, how the complex lived experience of such fact/value "amalgams" can be objectively investigated via the procedures of the human sciences which themselves have their origin and point of departure in the prescientific concerns and interests of the life world. We can begin to move toward a resolution of this problem by considering the manner in which the scientific approach to phenomena is constituted through a modification of our everyday experience of the life world.

In Being and Time, Martin Heidegger provides a compressed, but extremely insightful, account of the manner in which theoretical knowing arises through a modification of our everyday mode of being-in-the-world and of the ways of "seeing" characteristic of it." Briefly stated, Heidegger's point is that when we regard things from a theoretical or scientific point of view, we distance ourselves from direct practical engagement with them: things-within-the-world become ob- 
jects of reflection rather than objects of direct circumspective concern. Thus, something (e.g., a hammer) which is ordinarily seen as an item of equipment in a context of involvement relationships"within an equipmental totality comes to be seen, from the scientific perspective, in isolation from these involvement relationships, as, e.g., an entity with "mass." Likewise, from the scientific perspective, things lose their equipmental locations, their places, and are seen instead in abstracted spatio-temporal terms--as "worldpoints" in no way distinguishable from others, and thus amenable to quantification in mathematical terms. In a word, the scientific way of seeing (in contrast to that of circumspective concern) "objectifies" the phenomena it encounters within-the-world.

Heidegger further points out that the objectification characteristic of the changeover from the everyday to the theoretical attitude arises through a "thematizing projection" of entities encountered within-theworld. This thematization provides for a projection of world and the entities encountered within. it in a manner amenable to scientific conceptualization and analysis. Moreover, depending on what domain of entities, and what aspects of them, are specifically selected for investigation, thematization allows for the differentiation of a wide range of (specific) natural and human sciences. Thereafter, once the domain of research has been clearly defined, the precise methods of investigation may be worked out in detail. Thus, the thematization which characterizes the changeover from the everyday to the theoretical mode of "seeing" and "deliberating" accomplishes several things; it "comprises the original project of the object of investigation as such, the delineation of the domain of research, the determination of the methods to be used, the first orientation of the conceptual and discursive structure. and the linguistic means of expression."

Elaborating on Heidegger's account of the thematization which characterizes the scientific projection of entities within-the-world, Joseph Kockelmans has argued further that this thematization typically involves the procedures of formalization, functionalization, and quantification. Formalization here refers to the fact that in empirical science entities are typically determined and described with respect to their formal properties. Functionalization refers to the description and explanation of relations between formalized entities according to a general "if, then" scheme. Finally, quantification, a special mode of formalizing functionalization, permits the description of formalized phenomena and their interrelations by means of mathematical procedures. The great merit of this line of analysis is that it explains how theoretical science with its formal explanatory apparatus is possible, and in particular, it clarifies the theoretical foundations 
of the quantitative methodologies almost universally utilized today in the social as well as in the natural sciences. But, as Kockelmans notes, equally clearly. it points to the intrinsic limitations of the objectified empirical analysis of social phenomena: the phenomena are inevitably reduced and abstract in comparison with their richness in the world of lived experience.

Now, the reduction of phenomena to (merely) formalized and idealized elements, and their manipulation by purely logico-mathematical procedures may pose little problem with regard to the relatively "inanimate" objects of natural science, but it does pose significant problems for the human sciences whose subject matter bears on the meaning-laden events of the life world. In particular, how is the meaning-structure of man's orientation toward his life world and his experience of "intentionality-laden world facts" to be elucidated in the conduct of social inquiry, and how are the findings to be meaningfully related back to the living tradition from which they arise?

In response to this question, Kockelmans has argued that, while the-logico-empirical methods of the human sciences yield worthwhile and productive results with respect to man's behavior in the world, there is a need, if our researches are to do full justice to the complexity of man's being-in-the-world, to supplement purely empirical techniques (those characterized by a thematization which involves formalization, functionalization, and quantification) with the methods of "descriptive" and "interpretative" inquiry."

The descriptive phase of research has as its goal the uncovering of fundamental structures of man's lived experience in the social world. In addition to faithfully reflecting lived experience, these structures-like those of a Husserlian "regional ontology"--should be of a general and necessary kind. 10 Once elicited, these structures both guide the process of concept and theory formation employed in the empirical phase of research, and aid in the elucidation of the social and historical meaning of phenomena, carried out in the interpretative phase." The more universal of Weber's "ideal types" furnish good examples of descriptive structures. 12

In contrast to the investigation of universal structures carried out in the descriptive phase, the aim of the interpretative phase is "to understand the historical situation in which social phenomena arise and to show how they are incorporated in the context of a living tradition in which each individual of a society forms his identity."13 The interpretative phase is thus centrally concerned with the elucidation of the meanings which social actions and events have in their societal and historical context. Without it, the full significance of these life world occurences would 
remain unclarified and uncritically taken for granted. The more specific and situational of Weber's ideal types, those pertaining to concrete societies in their historical development, may serve as examples of interpretative concepts. 14

The foregoing remarks serve to clarify the point that, while the human sciences have their origin and point of departure in the world of lived experience, they aim to distance themselves from direct practical involvement with the everyday world, so that they can investigate its meaning and structures in a controlled and systematic fashion. More specifically, however, it has been noted that with regard to social phenomena, casual explanatory schema which deal with reduced and formalized data can only accomplish so much. Without descriptive and interpretative procedures, the quantified data of the purely empirical phase of research will neither be grounded in the fundamental structures of the life world nor will they be adequate to elucidate the cultural and historical meanings of the phenomena under investigation. Accordingly, if the "intentionality-laden world facts of lived experience," which are at the heart of social inquiry, are to be appropriately grasped, understood, and elucidated, a tripartite approach--comprising descriptive and interpretative as well as empirical moments--must be adopted with regard to the phenomena of the social world.

With this established, it is time to pose afresh the question of the criteria of objectivity appropriate to research in the human sciences. At the outset, it will be recalled, we had occasion to query the value neutrality of even the empirical phase of research. We will be in a better position to shed some additional light on this problem if we first consider the question of the objectivity of the descriptive and interpretative phases.

With respect to the descriptive phase, Kockelmans convincingly argues that the methods of free variation and especially of intentional analysis, as outlined by Husserl, 1 constitute appropriate methodological procedures for uncovering the general and necessary structures of life world phenomena--provided that, as argued by Merleau-Ponty, "is Husserl's conception of essences is reinterpreted from an existential point of view. ${ }^{27}$ The structures thus elicited provide, as we have noted, the foundations for the process of concept and theory formation with respect to the investigation of life world phenomena. Since the descriptive phase of research does not involve the use of mathematical type procedures, the conception of objectivity here is nonmathematical also. But, of course, there are other sorts of criteria operative to guide the impartiality and appropriateness of the analysis. Of particular importance here is what Schutz called the "postulate of adequacy," a criterion to ensure the compatability of 
the constructs of the social scientist with the construct of everyday life." Clearly. also, the logical postulates of non-contradiction, consistency, and coherence must be adhered to in this as weli as in all phases of the research process. Furthermore, as already noted, the descriptive procedures have their "natural extention" in the interpretative phase, and accordingly, descriptive research is also governed by the canons and principles operative in the latter mode.

The interpretative phase of social inquiry is concerned, as we see, with the societal meanings of life world phenomena in their historical and cultural context. Here, the attempt to preserve objectivity may seem to face its greatest challenge because we inquire directly into life world meanings and experiences which we have seen to be value-laden, and accordingly, in a sense, subjective. How, then, is objectivity to be preserved in this domain? In this regard, Kockelmans points out that, while the meaning of lived experience and its significance for social agents (actors) is never "objective" in the sense in which this term is used in the natural sciences, it is not really "subjective" either-in that "this meaning is intersubjectively shared by the members of a society and [is] thus intersubjectively accessible" to researchers. Kockelmans notes too that since it is the meanings and values of the social actors and not those of the scientist that are under investigation here, the threat of subjectivism is not so great as it may at first sight appear. Nonetheless, criteria must be established for the impartial interpretation of the societal meaning of the events and phenomena of the life world. In this regard, Kockelmans counsels the use of the hermeneutical rules of "canons" "whose goal it is to achieve intersubjective validity in regard to the results obtained via this type of understanding." "In particular, five canons must be applied to ensure the intersubjective validity of these interpretations.

Briefly stated, these canons require the following conditions to be met. 20

1. With a view to preserving the autonomy of the object, a phenomenon must be understood "from within itself"; thus, the phenomenon itself remains the primary and final source as well as the criterion for the legitimacy of interpretation.

2. Even where the original meanings of social actions or institutions have been covered up by secondary or tertiary layers of meaning, an interpretation must be searched for which makes the phenomena maximally reasonable (while, of course, preserving their autonomy).

3. Careful historical research must be undertaken, as necessary, so that the interpreter achieves the greatest possible familiarity with the phenomena whose meaning he wishes to understand interpretatively. 
4. Especially important is the hermeneutic circle. This canon emphasizes that our interpretation of phenomena must move back and forth--and in the process be corrected and deepened--between an understanding of the parts and an understanding of the whole. This process--appropriately termed a dialectical one--is "quasi-infinite, both on the side of our knowledge of the relevant wholes and on the side of their parts." Nonetheless, an interpretation can nearly always be reached which is genuinely adequate with regard to the phenomena under consideration.

5. Einally, "in all these steps the interpreter must try to show the meaning of a phenomenon for his own situation." That is to say, the understanding of the historical genesis and development of the social behaviors, actions, or institutions must eventuate in an application of the results of these researches to the current situation. A risk of prejudice or too hasty application--one which violates a preceding canon--enters here, of course. But, if the interpreter's prejudices or pre-judgments are made explicit and are critically examined--and one might add, themselves intersubjectively validated--this risk can be virtually eliminated.

In short, the interpretative canons outlined by Kockelmans enable the investigator to specify what Schutz calls the "objective meaning-contexts of subjective meaning-contexts." 2 "Their applicability to the investigation of the rich and complex meanings of life world phenomena gains further support in the context of Ricoeur's analysis of meaningful action considered as a text.22 clearly, within the interpretative and descriptive phases they provide appropriate standards of objective research--especially when understood in the context of the intersubjective processes of validation which we shall consider shortly. First, however-having now delineated the criteria of objectivity appropriate to the descriptive and interpretative phases of inquiry--we must return to the consideration of the criteria of objectivity appropriate to the empirical phase as such.

Typically, on the traditional value neutral accounts, the criteria of empirical objectivity are those commensurate with the deductive-nomological model of explanation and the hypothetico-deductive model of theory-testing (not withstanding some acknowledged difficulties in "translating" their application from the realm of the natural to that of the human sciences). However, this preference for logico-mathematical criteria leaves out of account the significant interpretative and valuational components involved in the investigation of empirical social phenomena, and on the whole seems to presuppose a ready-made domain of formalized data. Undoubtedly, the logico-mathematical criteria have significant application in the assessment 
of formalized and quantified data. But, as was noted at the outset, these data themselves have significance only within a much larger domain of inquiry, one which involves numerous interpretative and valuational elements. Thus, as has been noted above, the identification of a research problem, the construction of an appropriate research framework, the observation of selected phenomena, and the integration of results are all interpretative processes-and the logicomathematical manipulation of data has its significance only as part of this larger process. Indeed, while the performance of mathematical operations on the quantified data may itself be a purely mathematical affair, the quantification of phenomena is not; it too requires interpretative and selective procedures. ${ }^{3}$ If this line of argument is correct, then the empirical phase of research is as much an interpretative as a logical process, and it too should incorporate the canons of "objectivity" relevant to the more clearly interpretative phases.

The foregoing argument suggests that Ricoeur's text analogy and the specific procedures of interpretation, outlined by Kockelmans with respect to one aspect of the research process, are appropriate to all phases of research in the human sciences. Accordingly, as the development of Ricoeur's analogy suggests, the criteria of objectivity appropriate to social inguiry are better construed in terms of intersubjective validation which is arrived at through the mediation of conflicting interpretations, rather than in purely logicomathematical terms. The context of validation, in other words, is that of argumentation, wherein all interpretations may be challenged, and even "the final interpretation appears as a verdict to which it is possible to make appeal."2" This model of validation does not imply a value neutral stance in the traditional sense; rather it implies a kind of (intersubjective) "hermeneutic circle" in which any unwarranted subjective intrusions in the interpretative process may be corrected through the process of argumentation and criticism, engaged in by the community of appropriately qualified investigators.25 Furthermore, the context for the conduct of such validation procedures may appropriately be elaborated in terms of Habermas's specification of an "ideal speech situation" and the validity claims relevant to it.2 Needless to mention, throughout the process of validation of interpretations through criticism and argument, the social world itself remains the object - of inquiry and hence, the "touchstone" for the "verification" of interpretations.

The objectivity attained through the careful application of interpretative procedures in all phases of the social research process does not require the (impossible) exclusion of all interests and values on the part of the investigator; and in this sense, the 
process is not value neutral. However, it does require that all personal and subjective interests are subordinated to the value of impartial norms of inquiry, as specified by the community of scientific investigators. Accordingly, while individual interests may play a part in the selection of a problem to be investigated and even in the decision as to the methodological procedures to be employed in its investigation, the inguiry must, nevertheless, be carried through at every stage in accordance with the criteria of controlled and impartial investigation specified by the community of qualified investigators. The realization that these criteria are not (as the traditional model would have it) purely logical in character but inevitably involve valuational and interpretative components does not at all detract from the objectivity of social scientific research. For the interpretation of social phenomena, like the interpretations of texts, is a controlled procedure involving well-grounded criteria of adequacy and validity. In addition, as we have seen, the validation of the interpretative understanding and explanation of life world phenomena is not ultimately the prerogative of an isolated investigator, but depends rather on a well-structured process of argumentation and criticism carried on within the community of qualified investigators. Accordingly, the objectivity of social inquiry is attained rather through a process of controlled valuation than through one of value neutrality.

\section{NOTES}

${ }^{1}$ Value in Social Theory (New York: Harper, 1958), 54; cf. Gunnar Myrdal, objectivity in Social Research (New York: Pantheon Books, 1969 ), $5 \frac{1}{5}$.

${ }^{2}$ Value, 51-52; cf. Objectivity, 9, 51 .

'Value, 54; Objectivity. 55-56.

"See, e.g., Max Weber, "'Objectivity' in Social Science and Social Policy," in Understanding and Social Inquiry, ed. Fred Dallmayr and Thomas McCarthy (Notre Dame: University of Notre Dame Press, 1977), esp. 2729, 31-32.

${ }^{5}$ Radical Reflection and the origin of the Human Sciences (West Lafayette: Purdue University Press, 1980). Parenthetical references in the remainder of this section are to this work. 
'Being and Time, trans. $\therefore$ Macquarrie and $E$. Robinson (New York: Harper, 1962), 408-15. See also Joseph Kockelmans, On the Truth of Being: Reflections on Heidegger's Later Philosophy (Bloomington: Indiana University Press, 1984), 209-18; A. Stewart, "Heidegger's Transcendental and Phenomenological 'Justification' of Science," in Analecta Husserliana XV, eds. A$M$ Tymieniecka and $C$. Schrag (Boston: Reidel, 1983).

'Joseph Kockelmans, "Heidegger on the Essential Difference and Necessary Relation between Philosophy and Science," in Phenomenology and the Natural Sciences, eds. J. Kockelmans and T. Kisiel (Evanston: Northwestern University Press, 1970), 157.

- "Heidegger on the Essential Difference," 160-61.

'See, e.g.. Joseph Kockelmans, "Theoretical Problems in Phenomenological Psychology," in Phenomenology and the Social Sciences, ed. M. Nathanson (Evanston: Northwestern University Press, 1973), 256-57.

${ }^{\circ}$ See Edmund Husserl, Ideas, trans. W. Boyce Gibson (New York: Humanities Press, 1931); cf. also Joseph Kockelmans, "Theoretical Problems in Phenomenological Psychology," 258-59.

"Joseph Kockelmans, "Toward an Interpretative or Hermeneutic Social Science," Graduate Faculty. Philosophy Journal 5 (1975): 78, 94 .

12 Joseph Kockelmans, "Reflections on Social Theory," Human Studies 1 (1978): 11-14.

"3"Toward an Interpretative Social Science," 81. 14.

"Kockelmans, "Reflections on Social Theory," 11-

${ }^{15}$ Phanomenologische Psychologie (The Hague:

1" Phenomenology of Perception, trans. C. Smith (New York: Humanities Press, 1962), xiv-xvi.

"Kockelmans, "Theoretical Problems in Phenomenological Psychology." 266, 270.

"Alfred Schutz, "Concept and Theory Formation in the Social Sciences," in Understanding and Social
Inquiry, 237 .

19 "Toward an Interpretative Social Science," 78-83.

20 "Toward an Interpretative Social Science," 83-86. 
${ }^{2}$ The Phenomenology of the Social World, trans. 3 . Walsh and F. Lehnert (Evanston: Northwestern University Press, 1967), 241.

22 paul Ricoeur, "The Model of the Text: Meaningful Action Considered as a Text," in Understanding and Social Inquiry, 316-34.

2'As Hopf notes, the view that "with quantification, genuinely 'interpretative' or qualitative procedures are left behind and the field of traditional social scientific research is entered, is not only misleading but also naive. It distracts from the examination of the problems concerning meaning which are connected with the different attempts as quantification" (see "Norms and Interpretations--Some Methodological and Theoretical Problems in the Collection and Analysis of Subjective Accounts in Quantitative Research," Human Studies 6 (1983): 12).

" "The Model of the Text," 332 .

${ }^{25} \mathrm{Cf}$. Karl-otto Apel, "Types of Social Science in the Light of Human Interests of Knowledge," Social Research 44 (1977): 456-59.

26See, e.g., Thomas McCarthy, The Critical Theory of Jurgen Habermas (Cambridge: MIT Press, 1978), $\frac{\text { 307- }}{10}$ 10 . 